Case report

\title{
Liver Transplantation as a Cure for Neurologically Advanced Wilson's disease. Learning More from Experience
}

Marina Moguilevitch*, Tracey Straker

Montefiore Medical Center, 111 East 210th street, Bronx, NY, USA; E-Mails: mmoguile@montefiore.org; tstraker@montefiore.org

* Correspondence: Marina Moguilevitch; E-Mail: mmoguile@montefiore.org

Academic Editor: Yasuhiko Sugawara

Special Issue: Pediatric Liver Transplantation

OBM Transplantation

2020, volume 4, issue 4

doi:10.21926/obm.transplant.2004123
Received: July 05, 2020

Accepted: November 02, 2020

Published: November 11, 2020

\begin{abstract}
Clinical presentation and progression of Wilson's disease can be diverse in different groups of patients. While young children most likely to present with acute or chronic liver failure, older children and adults may exhibit extrahepatic manifestation like neuropsychiatric, cardiac, renal, pancreatic and several others. Diagnosis of Wilson's disease is based on the combination of specific clinical findings, laboratory and genetic testing. There are different modalities of treatment available for this condition. Liver transplantation has become a acceptable treatment option for acute and chronic liver failure related to Wilson's disease. It allows for resolution of metabolic disorder and hepatic disease progression. There are no definitive criteria and established outcomes in transplantation of the patients with Wilson's disease who have different degree of neuropsychiatric presentation. Therefore, it is very important to create specific criteria for selecting of these patients before transplantation and to have short-and long-term follow up system to improve their outcome and survival.
\end{abstract}

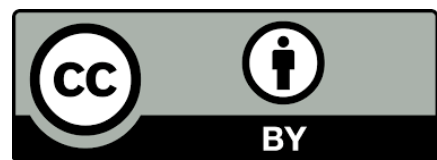

(C) 2020 by the author. This is an open access article distributed under the conditions of the Creative Commons by Attribution License, which permits unrestricted use, distribution, and reproduction in any medium or format, provided the original work is correctly cited. 


\section{Keywords}

Pediatric liver transplant; Wilson's disease; indications for liver transplant in Wilson's disease; selection criteria for liver transplant in Wilson's disease; outcomes after liver transplant for Wilson's disease

\section{Introduction}

Liver transplantation remains the primary treatment option for patients with acute liver failure secondary to Wilson's disease. Without transplantation, mortality is very high. However, the indications and time frame for liver transplantation in patients with Wilson's disease which progresses to cirrhosis are still not clearly identified in the literature. There are multiple reasons for the disease progression: some patients with advanced Wilson's disease were not started on copper chelating agents in a timely manner, other did not respond to treatment or demonstrated poor adherence. The rate of progression of liver disease with development of cirrhosis and neuropsychiatric complications is usually multifactorial and the decision of transplanting these patients is very complex. Compiling the indications for liver transplantation in this patient population is extremely important and it is the focus of this discussion. We would like to share our unique experience and outcome after liver transplantation of a patient who suffered significant neurologic damage from the advanced Wilson's disease.

\section{Case}

A 15 year-old, $28 \mathrm{~kg}$ male, without any medical conditions developed signs of liver disease at the age of 9 when he was first diagnosed with elevated bilirubin. His disease rapidly progressed with development of drooling, headaches, and speech disturbance. He failed Penicillamine and Zinc therapies, and presented to our center with tremors, stiffness, developmental and cognitive delays, dysarthria, dysphagia, and inability to ambulate. According to the family, the child was compliant with the treatment. At the time of admission he was dependent on G-tube feedings for nutrition and was wheelchair-bound. His Magnetic Resonance Imaging (MRI) scan of the brain showed significant volume loss, atrophy, and mineralization of the basal ganglia and substantia nigra (Figure 1). Ophthalmologic examination demonstrated Kayser-Fleischer rings. Liver biopsy performed shortly after admission, revealed signs of cirrhosis, mild portal inflammation, bile duct proliferation, and focally increased stainable copper on Rhodanine stain. Treatment with Trientine and Zinc failed to halt the progression of neurologic symptoms. 


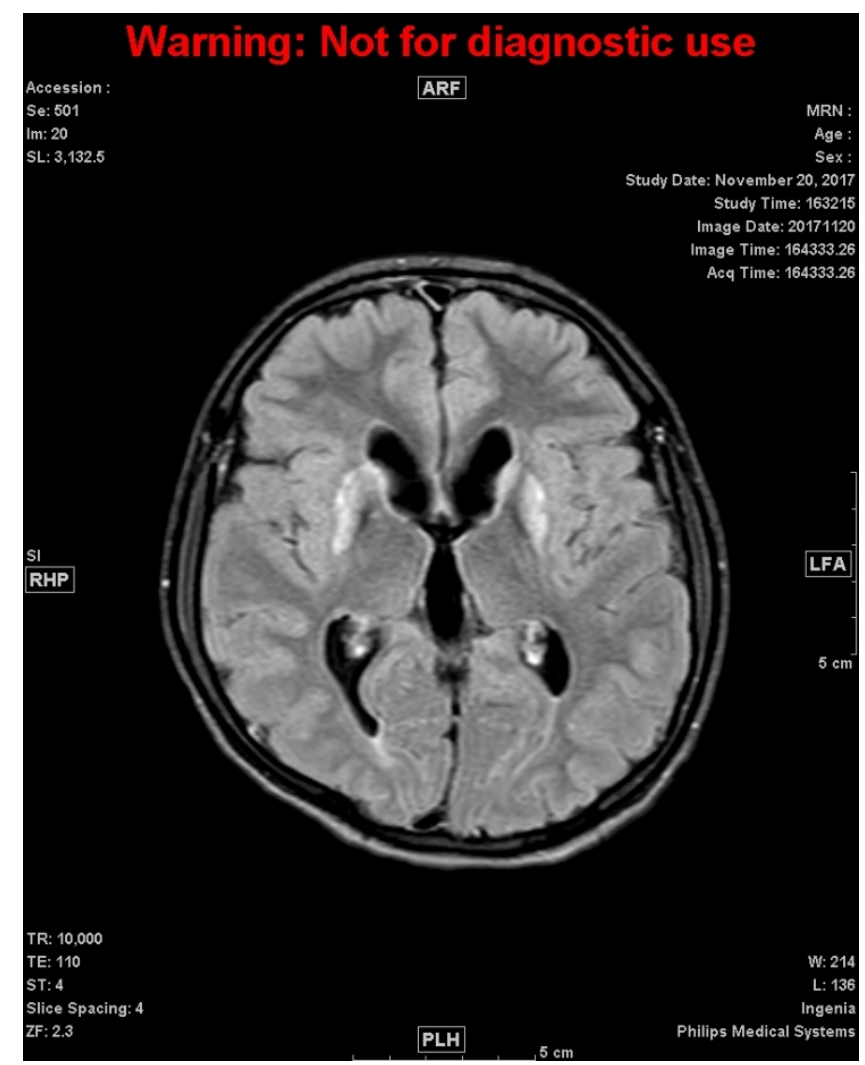

Figure 1

His laboratory findings were significant for alkaline phosphatase $230 \mathrm{IU} / \mathrm{L}$, hematocrit 28 percent, albumin $3.2 \mathrm{~g} / \mathrm{dl}$, total bilirubin $2.3 \mathrm{mg} / \mathrm{dl}$, and direct bilirubin $0.6 \mathrm{mg} / \mathrm{dl}$, ceruloplasmin $6 \mathrm{mg} / \mathrm{dL}, 24$ hours urine copper $240 \mathrm{mcg} / \mathrm{dL}$. The rest of the laboratory findings were within normal limits.

After thorough multidisciplinary evaluation and bioethical committee approval, the patient was listed for liver transplant with Pediatric End Stage Liver Disease (PELD) score of 40. Additional points were given for the failure to thrive and devastating neurologic comlications of the disease. The transplant team and the patient's family were aware that neurological symptoms may not be reversible after the surgery. There was no living donor liver offer available for this patient. Shortly after listing the patient received deceased donor $A B O$ compatible whole liver graft. The liver transplant was uneventful, and required no blood or blood product transfusion. No signs of significant portal hypertension were noticed during the surgery. Eight months after transplantation, the patient became verbal with normal swallowing, gained wait, and demonstrated ability to ambulate. His tremors and stiffness were completely gone. We were able to observe complete resolution of his neurologic deficits in twelve months after transplantation.

\section{Discussion}

Wilson's disease (WD) is an inherited autosomal recessive disorder of copper metabolism that affects approximately 1 in 30,000 people. The carrier rate of this disease is 1 in 90 [1]. The disease results from dysfunction of the copper-transport adenosine triphosphatase mechanism in the ATP7B gene in the liver. This gene is responsible for excreting copper into the bile [2, 3]. Failure to incorporate copper into the ceruloplasmin is also a consequence of the dysfunctional ATP7B protein. The hepatic production and secretion of the abnormal protein apoceruloplasmin results in 
decreased levels of ceruloplasmin, which is found in most WD patients [4]. The abundance of disease-specific mutations and their location at multiple sites across the genome have made molecular genetic diagnosis difficult. The subsequent copper accumulation, primarily in liver and brain, leads to hepatic and neurological manifestations [5].

Wilson's disease has a highly variable onset and clinical course [6-8]. In many cases, symptoms of the disease are nonspecific. Children and young adults are more likely to present with progression of liver disease. The presentation can vary from fulminant hepatic failure to a slow progression of decompensated cirrhosis. Late onset WD presents with neuropsychiatric symptoms, such as tremor, dysarthria, ataxia, rigidity, dyskinesia, cognitive impairment, and mood disturbances. Many patients with psychiatric or neurologic manifestations may have asymptomatic cirrhosis. Extra-hepatic manifestations include renal symptomatology such as aminoaciduria, nephrolithiasis, arthritis, premature osteoporosis, cardiomyopathy, hyperparathyroidism, pancreatitis, and infertility [9-14].

According to the latest guidelines published by the European Society for Pediatric Gastroenterology, Hepatology and Nutrition (ESPGHAN), European Association for Study of the Liver Disease (EASL), and Indian National Association for Study of the Liver (INASL)the diagnosis of WD is based on the combination of biochemical laboratory tests assessing copper metabolism, a broad spectrum of clinical features, and molecular analysis of the mutations in the ATP7B gene [15-17]. Corneal copper deposition called the Kayser- Fleisher ring, hemolytic anemia due to deficiency of ceruloplasmin, and neurologic symptoms are considered to be the most common clinical symptoms. Twenty-four hours urine copper, hepatic copper concentration, ceruloplasmin, and the presence of the ATP7B gene mutation are laboratory tests used to confirm the final diagnosis of WD.

In 2001, at the 8th International conference on Wilson's and Menkes disease in Leipzig the scoring system for the diagnosis of WD was discussed. A combination of clinical and biochemical tests with the score ranging from 0 to 4 for each test were developed. The aim of this system was to provide objective criteria with high sensitivity and specificity for the diagnosis of Wilson's disease. The patients with the total score of at least 4 are diagnosed with WD. Approximately five percent of all WD patients present with new onset acute liver failure, and require emergency liver transplantation that is life saving [18]. According to the studies by McCullough et al and Schilisky et al, the diagnosis of Wilson's disease in the acute liver failure setting is more challenging because traditional copper metabolism parameters are less reliable, and specific $[19,20]$. Korman et el demonstrated that the ratio of alkaline phosphatase to total serum bilirubin with a value of less than 2, in combination with the ratio of aspartate aminotransferase (AST) to alanine aminotransferase (ALT) with a value of greater than 2.2, has $100 \%$ sensitivity and specificity [21]. These tests are proven to be reliable for the adult patient population with a relatively low Model for End Stage Liver Disease (MELD) score. In pediatric patients, bone-derived alkaline phosphatase can play a role in making the ratio of AST to ALT of 2.2 less reliable. Koppikar et al [22] proposed the Wilson's scoring index, which is composed of the international normalized ratio (INR), AST, white blood cells, albumin, and bilirubin for pediatric patients.

Until transplantation can be performed, temporizing measures like plasmapheresis [23], exchange transfusion [24], fractionated plasma separation and absorption (FPSA) [25], and molecular adsorbent recycling system (MARS) [26] can be helpful.

Liver transplantation for chronic Wilson's disease is the definitive treatment for the metabolic disorder, and resolution of the hepatic failure associated with WD. Liver transplantation reverses biochemical and clinical futures of Wilson's disease, but its effect on neurologic symptoms is not 
very well established. The first successful resolution of neurological disorders after liver transplantation for chronic Wilson's disease was reported in mid 90's [27-29]. The decision to perform liver transplantation in these cases was based on deteriorating neurologic status with relatively stable liver function.

Likewise, Kassman et al [30] reported the case of a 22 year-old male with advanced neurological impairment and significant psychiatric manifestations secondary to Wilson's disease. The patient demonstrated normalization of liver metabolic function after liver transplantation. Unfortunately, neurological recovery was slow and incomplete, while the psychiatric manifestations never improved. He committed suicide 43 months after transplantation.

There are many studies that retrospectively analyzed liver transplant patients with Wilson's disease and varying degrees of neurological and psychiatric deterioration [31-34]. All patients showed an improvement, or complete disappearance of the neurological symptoms. The notion that better results can be achieved in transplanting patients with mild to moderate neurological deterioration has not been proven yet [35]. Wang et al demonstrated that results are favorable in patients with advanced neurological deficits after living-related liver transplants [32]. However, several studies have reported death as an outcome of liver transplantation for patients with neurological manifestations [27-33]. Despite the death of several of their patients, the authors have advocated liver transplantation for neurologically challenged patients.

There is minimal data available on the predictors of outcome on transplanted patients with varying degrees of neuropsychiatric symptoms of Wilson's disease, and their long-term survival. Medici et al presented a retrospective multicenter analysis of the outcome of 37 patients transplanted for Wilson's disease [36]. More than a third of the patients had multiple presentations of neuropsychiatric compromise. The authors used a scoring system to retrospectively assess the patient's pre-and post-operative neurological status. Reported patient and graft survival at 3 months, 12 months, 3 years, 5 years, and 10 years after transplantation were, respectively, 91.8\%, $89.1 \%, 82.9 \%, 75.6 \%, 58.8 \%$, and $85.3 \%, 83 \%, 77.1 \%, 70.3 \%, 47.2 \%$.

According to the authors, neurologic symptoms significantly improved or completely resolved in $70 \%$ of the patients after transplantation, but survival in this cohort was lower than in patients with liver disease alone $(P=0.04)$. Wang et al demonstrated similar results in his retrospective study of eighteen living related liver transplants for Wilson's disease [37]. Among these eighteen patients, seven had mild to moderate neurological involvement. All showed improvement of their symptoms after surgery, but also demonstrated a slightly lower survival rate. The follow up time in this study ranged from 2 to 32 months.

Guillaud et al studied the biggest cohort of the Wilson's disease patients presented in the literature who underwent liver transplantation [38]. They analyzed retrospectively medical records of 121 French patients transplanted for WD, seventy-five were adults (median age 29 years, (18-66)) and 46 were children (median age 14 years, (7-17)). The indications for liver transplantation were fulminant hepatic failure, decompensated cirrhosis, and severe neurological disease. Multivariate analysis of different groups of patients with different indications for transplantation concluded that liver transplantation allowed to achieve good long-term outcome, including improvement of renal function.

Two latest papers by Poujois et al [39] and Ferrarese et al [40] specifically looked at the outcomes of Wilson's disease patients transplanted for neurological indications. Both articles recommended 
very careful approach to patients selection for the liver transplant surgery and indicated limited benefit of this procedure to improve neuropsychiatric symptoms or signs of the disease.

\section{Conclusions}

Liver transplantation remains the treatment of choice for acute liver failure related to Wilson's disease. Transplantation is indicated when patients develop cirrhosis, become unresponsive, or have never been on cooper chelating agents. Liver transplantation is a good option for symptom improvement or sometimes complete cure in patients that develop neurological deficits related to Wilson's disease. Nonetheless, there is not enough data available to draw a conclusion about the clear beneficial effect of liver transplantation in all cases of neurologically affected Wilson's disease patients. It is more research needed to look at larger cohorts in order to provide better stratification for postoperative survival and long term follow up of these patients. Our case can contribute to the ongoing effort to identify indications, predicting factors of cure, and survival after liver transplantation for the patients with chronic Wilson's disease.

\section{Acknowledgments}

The authors would like to thank the patient's family for supporting us in sharing this case report.

\section{Author Contributions}

All authors participated in manuscript creation, review process, and revisions.

\section{Competing Interests}

The authors have declared that no competing interests exist.

\section{References}

1. Loundianos G, Gitlin JD. Wilson's disease. Semin Liver Dis. 2000; 20: 353-364.

2. Bull PC, Thomas GR, Romments JM, Forbes JR, Cox DW. The Wilson disease gene is a putative copper transporting P-type ATPase similar to the Menkers gene. Nat Gen. 1993; 5: 327-337.

3. Yamaguchi $Y$, Heiney ME, Gitlin JD. Isolation and characterization of human liver cDNA as a candidate gene for Wilson disease. Biochem Biophys Res Commun. 1993; 197: 271-277.

4. Holzman NA, Gaumnitz BM. Studies on the rate of release and turnover of ceruloplasmin and apoceruloplasmin in rat plasma. J Biol Chem. 1970; 245: 2354-2358.

5. Roberts EA, Schilsky ML. A practice guideline on Wilson disease. Hepatology. 2003; 37: 14751492.

6. Ferenci P, Czionkowska A, Merle U, Ferenc S, Gromadzka G, Yurdadin C, et al. Late onset Wilson's disease. Gastroenterology. 2007; 132: 1294-1298.

7. Merle U, Schafer M, Ferenci P, Stremmel W. Clinical presentation, diagnosis and long-term outcome of Wilson's disease: A cohort study. Gut. 2007; 56: 115-120.

8. Stremmel W, Meyerrose KW, Niederau C, Hefter H, Kreuzpainter G, Strohmeyer G. Wilson disease: Clinical presentation, treatment, and survival. Ann Intern Med. 1991; 115: 720-726. 
9. Nakada SY, Brown MR, Rabinowittz R. Wilson's disease presenting as symptomatic urolithiasis: A case report and review of the literature. J Urol. 1994; 152: 978-979.

10. Goldin DN, Walshe JM. Arthropathy of Wilson's disease. Study of clinical and radiological features in 32 patients. Ann Rheum Dis. 1997; 36: 99-111.

11. Hlubocka Z, Maracek Z, Linhart A, Kejrova E, Pospisilova L, Martazek P, et al. Cardiac involvement in Wilson disease. J Inherit Metab Dis. 2002; 25: 269-277.

12. Carpenter TO, Carnes Jr DL, Anast CS. Hypoparathyroidism in Wilsosn's disease. N Engl J Med. 1983; 309: 873-877.

13. Weizman Z, Picard E, Barki Y, Moses S. Wilson's disease associated with pancreatitis. J Pediatr Gastroenterol Nutr. 1988; 7: 931-933.

14. Tarnacka B, Rodo M, Cichy S, Czlonkowska A. Procreation ability in Wilson's disease. Acta Neurol Scand. 2000; 101: 395-398.

15. Socha P, Janczyk W, Dhawan A, Baumann U, D'Antiga L, Tanner S, et al. Wilson's disease in children: A position paper by the hepatology committee of the european society for paediatric gastroenterology, hepatology and nutrition. J Pediatr Gastroenterol Nutr. 2018; 66: 334-344.

16. European Association for Study of the Liver. EASL clinical practice guidelines: Wilson's disease. J Hepatol. 2012; 56: 671-685.

17. Nagral A, Sarma SM, Matthai JK, Kukkle LP, Devarbhavi H, Sinha S, et al. Wilson's disease: Clinical practice guidelines of the indian national association for study of the liver, the Indian society of pediatric gastroenterology, hepatology and nutrition, and the movement disorder society of India. J Clin Exp Hepatol. 2019; 9: 74-98.

18. Ostapowicz G, Fontana RJ, Schiodt FV, Larson A, Davern TJ, Han SH, et al. Results of prospective study of acute liver failure at 17 tertiary care centers in the United States. Ann Intern Med. 2002; 137: 947-954.

19. McCullough AJ, Fleming CR, Thistle JL, Baldus WP, Ludwig J, McCall JT, et al. Diagnosis of Wilson's disease presenting as fulminant hepatic failure. Gastroenterology. 1983; 84:161-167.

20. Schilsky ML. Overcoming obstacles to the diagnosis of Wilson's disease. Gastroenterology. 1997; 113: 350-353.

21. Korman JD, Volenberg I, Balko J, Webster J, Schiodt FV, Squires Jr RH, et al. Screening for Wilson disease in acute liver failure: A comparison of currently available diagnostic tests. Hepatology. 2008; 48: 1167-1174.

22. Dhawan A. Evaluation of the scoring system for the diagnosis of Wilson's disease in children. Liver Int. 2005; 25: 680-681.

23. Asfaha S, Almansori M, Qarni U, Gutfreund KS. Plasmapheresis for hemolytic crisis and impending acute liver failure in Wilson disease. J Clin Apher. 2007; 22: 10-14.

24. Kiss JE, Berman D, Van Thiel D. Effective removal of cupper by plasma exchange in fulminant Wilson disease. Transfusion. 1998; 38: 327-331.

25. Skwarek A, Grodzicki M, Nyckowski P, Kotulski M, Zieniewick K, Michalowicz B, et al. The use prometus FPSA system in the treatment of acute liver failure: Preliminary results. Transplant Proc. 2006; 38: 209-211.

26. Sen S, Felldin M, Steiner C, Larsson B, Gillett GT, Olausson M, et al. Albumin dialysis and Molecular Adsorbents Recirculating System (MARS) for acute Wilson's disease. Liver Transpl. 2002; 8: 962-967. 
27. Mason AL, Marsh W, Alpers DH. Intractable neurological Wilson's disease treated with orthopnic liver transplantation. Dig Dis Sci. 1993; 38: 1746-1750.

28. Schumacher G, Platz KP, Mueller AR, Neuhaus R, Steinmüller T, Bechstein WO, et al. Liver transplantation treatment of choice for hepatic and neurological manifestations of Wilson's disease. Clin Transplant. 1997; 11: 217-224.

29. Bax RT, Hassler A, Luck W, Hefter H, Krägeloh-Mann I, Neuhaus P, et al. Cerebral manifestations of Wilson's disease successfully treated with liver transplantation. Neurology. 1998; 51: 863865.

30. Kassman N, Witt N, Kneteman N, Bain VG. Liver transplantation for neuropsychiatric Wilson disease. Can J Gastroenterol. 1998; 12: 65-68.

31. Eghtesad B, Nezakatgoo N, Geraci LC, Jabbour N, Irish WD. Liver transplantation for Wilson's disease: A single-center experience. Liver Traspl Surg. 1995; 5: 467-474.

32. Wang XH, Cheng F, Zhang F, Li XC, Kong LB, Li GQ, et al. Living-related liver transplantation for Wilson's disease. Transpl Int. 2005; 18: 651-656.

33. Marin C, Robles R, Parilla G, Ramirez P, Bueno FS, Parilla P. Liver transplantation in Wilson's disease are its indications established? Transplant Proc. 2007; 39: 2300-2301.

34. Geissler I, Heinemann K, Rohm S, Hauss J, Lamesch P. Liver transplantation for hepatic and neurological Wilson's disease. Transplant Proc. 2003; 35: 1445-1446.

35. Stracciari A, Tempestini A, Borghi A, Guarino M. Effect of liver transplantation on neurological manifestation in Wilson disease. Arch Neurol. 2000; 57: 384-386.

36. Medici V, Mirante VG, Fassati LR, Pompili M, Forti D, Del Gaudio M, et al. Liver transplantation for Wilson's disease: The burden of neurological and psychiatric disorders. Liver Transpl. 2005; 11: 1056-1063.

37. Wang XH, Zhang F, Li XC, Cheng F, Li J, Li GQ, et al. Eighteen living related liver transplants for Wilson's disease: A single-center. Transplant Proc. 2004; 36: 2243-2245.

38. Guillaud O, Dumortier J, Sobesky R, Debray D, Wolf $P$, Valemmens C, et al. Long term results of liver transplantation for Wilson's disease: Experience in france. J Hepatol. 2014; 60: 579-589.

39. Poujois A, Sobensk R, Meissner WG, Brunet AS, Broussolle E, Laurencin C, et al. Liver transplantation as a rescue therapy for severe neurologic forms of Wilson disease. Neurology. 2020; 94: 2189-2202.

40. Ferrarese A, Morelli MC, Carrai P, Milana M, Angelico M, Perricone G, et al. Outcomes of liver transplant for adults with Wilson's disease. Liver Transplant. 2020; 26: 507-516. 


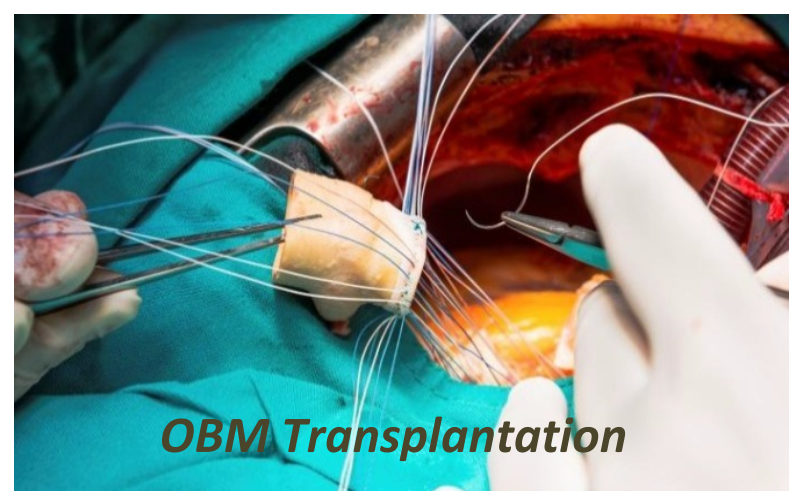

Enjoy OBM Transplantation by:

1. Submitting a manuscript

2. Joining in volunteer reviewer bank

3. Joining Editorial Board

4. Guest editing a special issue

For more details, please visit:

http://www.lidsen.com/journals/transplantation 